\title{
DETERMINAÇÃO DO ÍNDICE DE QUALIDADE DA ÁGUA DO ARROIO ESPERANÇA
}

\author{
Determination of the Index of Water Quality \\ in Esperança Stream
}

Pedro Daniel da Cunha Kemerich, Rodrigo Ferreira da Silva e

Patricia Tambosi Reque

eng.kemerich@yahoo.com.br

Universidade Federal de Santa Maria/CESNORS

\begin{abstract}
Resumo
O Arroio Esperança, situado em Santa Maria - RS, encontra-se em uma microbacia com situações de urbanização tanto regular quanto irregular. Através das perturbações antrópicas, a qualidade dessa água tem sido alterada negativamente. Nesse aspecto, trabalhos que visam a melhorar sua qualidade são necessários para prever sua recuperação. Este trabalho teve como objetivo realizar o diagnóstico da qualidade da água de uma microbacia urbana com o uso do Índice de Qualidade de Água (IQA). O trabalho foi desenvolvido na microbacia urbana do Arroio Esperança, localizado no município de Santa Maria-RS. As coletas de amostras da água foram realizadas durante os meses de julho, agosto, setembro e outubro de 2007 , nos pontos de mínima e máxima vazão do arroio. Os parâmetros analisados foram temperatura, $\mathrm{pH}, \mathrm{OD}$, DBO, turbidez, coliformes fecais, nitrato, fósforo e resíduos totais fixos. A água foi classificada pelo índice de qualidade como ruim, tendo como principal responsável pela sua degradação a presença de matéria orgânica, decorrente do lançamento de esgotos.
\end{abstract}


Palavras-chave: Índice de Qualidade de Água, contaminação, esgoto.

\section{Abstract}

The Esperança creek, located in Santa Maria - RS, is in a watershed with both regular and irregular situations of urbanization. Through human disturbance the water quality has been negatively altered. In that aspect, works that aim to improve its quality are needed to achieve its recovery. This work has as objective to realize the diagnosis of water quality of an urban watershed using the Water Quality Index (WQI). The study was developed at the urban watershed Esperança Creek, located in Santa Maria-RS. The collection samples of water were executed during the months of July, August, September and October 2007, at the minimum and maximum points of flow of the stream. The analyzed parameters were temperature, $\mathrm{pH}$, dissolved oxygen, $\mathrm{BOD}$, turbidity, fecal coliform, nitrate, phosphorus and total fixed residues. The water was classified as poor by the quality index, with the presence of organic substance as the major responsible for its degradation resulting from the dumping of sewage.

Keywords: Water Quality Index, contamination, sewer.

\section{Introdução}

Embora dependam da água para a sobrevivência e para o desenvolvimento econômico, as sociedades humanas poluem e degradam esse recurso. A diversificação dos usos múltiplos, o despejo de resíduos líquidos e sólidos em rios, lagos e represas e a destruição das áreas alagadas e das matas de galeria têm produzido contínua e sistemática deterioração e perdas extremamente elevadas em quantidade e qualidade da água (TUNDISI, 2003).

O conceito qualitativo da água é muito mais abrangente do que a caracterização da água pela fórmula $\mathrm{H}_{2} \mathrm{O}$ (VON SPERLING, 1996). A água pura é um líquido incolor, inodoro, insípido e transparente. Entretanto, nunca é encontrada no seu estado de absoluta pureza, por ser um solvente universal, contendo várias impurezas como algas, areia, argilas, minerais e compostos orgânicos. Essa ótima solubilidade é aumentada pela solubilização de dióxido de carbono existente na atmosfera e no solo, como resultado da decomposição de matéria orgânica (VON SPERLING, 1996). A qualidade da água não se refere ao grau de pureza 
absoluto ou próximo deste, mas sim a um padrão mais próximo possível do natural da água, ou seja, como ela se encontra nas nascentes, antes do contato do homem (BRANCO, 1991). O termo "qualidade de água" se trata das características físico-químicas e biológicas e, dependendo dessas características, são determinados diversos destinos para a água (MERTEN e MINELLA, 2002)

Os principais tipos de poluição aquática são a orgânica, microbiana e a inorgânica. A poluição orgânica é caracterizada pela presença de matéria orgânica na água. Assim, quanto maior a quantidade de matéria orgânica disponível, maior será a população de organismos que a decompõem, portanto maior será a quantidade de oxigênio consumida (NUVOLARI, 2003). A poluição microbiana é resultante da descarga de resíduos humanos que possui grande variedade de patógenos, entre eles bactérias, vírus, protozoários ou organismos multicelulares, que podem causar doenças gastrointestinais (TUNDISI, 2005). Para a quantificação e qualificação microbiológica, os coliformes são os indicadores de poluição fecal mais empregados, pois estão sempre presentes no trato intestinal humano e de animais de sangue quente, sendo eliminados em grande número pelas fezes. A poluição inorgânica é causada por compostos inorgânicos, os quais se dividem em dois grupos muito gerais: o grupo dos nutrientes e o grupo das toxinas. Algumas toxinas não são degradáveis e, quando ocorrer bioacumulação, podem causar problemas a seres humanos e peixes (CORRÊA, 2004). No grupo dos nutrientes, encontram-se o nitrato e o fósforo. A presença desses nutrientes favorece o crescimento descontrolado das populações de algas e plantas aquáticas (eutrofização), com concomitante aumento de odores e gosto na água, que, ao se decomporem, consomem grandes quantidades de oxigênio. Os nitratos podem ocorrer em águas originárias de esgotos domésticos e indústrias ou da drenagem de áreas fertilizadas, podendo ser indicador cronológico da carga poluidora (esgoto), e os fósforos de alguns detergentes e sabões em pó (CERETTA, 2004).

O uso de indicadores de qualidade de água consiste no emprego de variáveis que se correlacionam com as alterações ocorridas na microbacia. O Comitê de Preservação, Gerenciamento e Pesquisa da Bacia do Rio dos Sinos (COMITESINOS, 1990) aponta que o Índice de Qualidade da Água (IQA) indica, de modo sintetizado, a qualidade da água. Desse modo, esse índice pode ser uma alternativa que visa a resumir as 
variantes analisadas em um número, possibilitando analisar a evolução da qualidade da água no tempo e no espaço, facilitando, dessa forma, a interpretação de extensas listas de variáveis ou indicadores (BILICH e LACERDA, 2005). Para a avaliação da qualidade da água, tem sido utilizado o Índice de Qualidade da Água (IQA), desenvolvido pela National Sanitation Foundation (NSF), por meio de uma pesquisa realizada com profissionais de distintas especialidades relacionadas a qualidade da água, que indicaram os parâmetros mais significativos, bem como seu peso relativo na composição do índice final (BROWN e McCLELAND, 1970).

Diante do que foi exposto, o trabalho teve como objetivo determinar a qualidade da água do Arroio Esperança, localizado em Santa Maria RS, por meio do Índice de Qualidade da Água (IQA) e quais os parâmetros que mais contribuem para a qualidade determinada.

\section{MATERIAL E MÉTODOS}

O trabalho foi realizado no município de Santa Maria, região central do Estado do Rio Grande do Sul, entre as coordenadas geográficas $29^{\circ} 43^{\prime}$ de latitude sul e $53^{\circ} 49^{\prime}$ de longitude oeste (Figura 1).

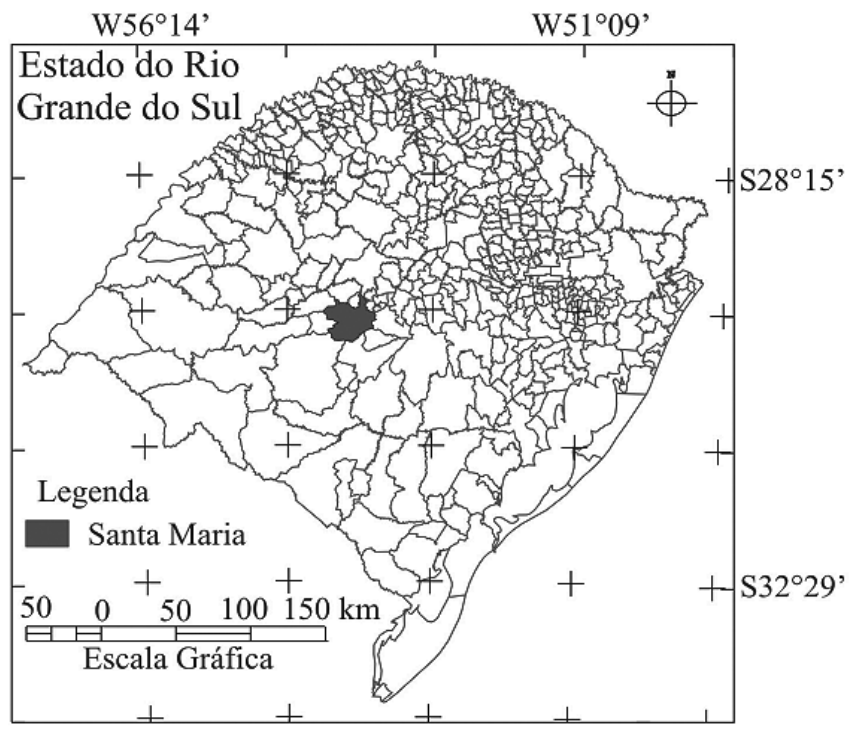

Figura 1 - Mapa de Localização da cidade de Santa Maria-RS. 
A área de estudo compreende a Microbacia Hidrográfica do Arroio Esperança (Figura 2), que está localizado na área urbana de Santa Maria, desaguando no Arroio Picadinha, afluente do rio Vacacaí. A Microbacia Hidrográfica do Arroio Esperança é caracterizada em duas situações: inicialmente no percurso norte da cidade (sentido leste-oeste), marcada pela ocorrência da urbanização densa, e posteriormente no percurso oeste (sentido norte-sul), pela urbanização menos densa (MELLO et al.,1996).

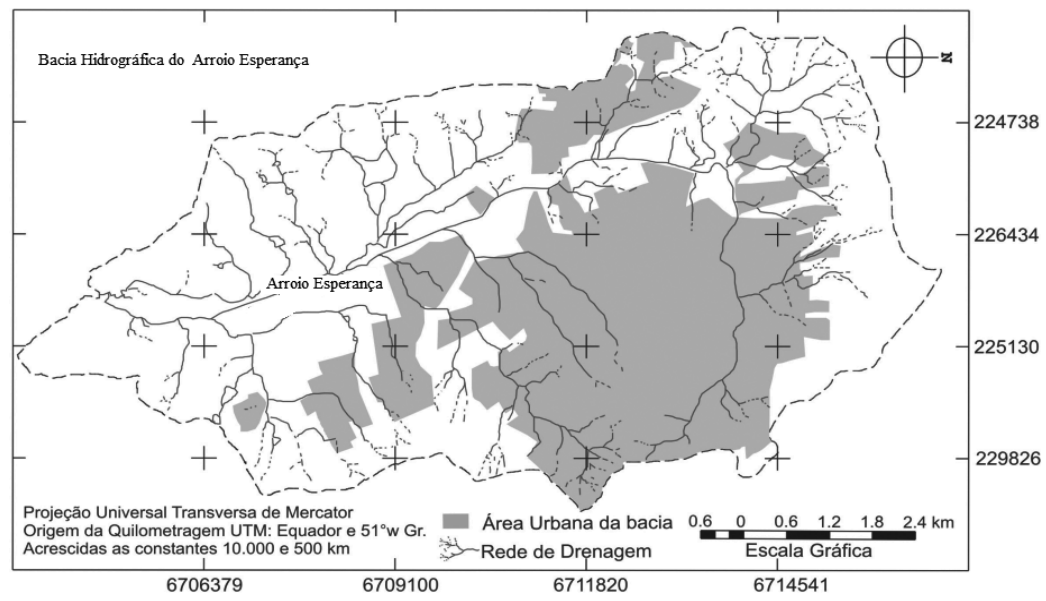

Figura 2 - Mapa de localização da Microbacia do Arroio Esperança em Santa Maria, RS (UCKER et al., 2009).

O período de amostragem compreendeu os meses de julho, agosto, setembro e outubro de 2007, com frequência mensal, no Arroio Esperança. O ponto de amostragem foi em uma Calha Parschall (Figura 3), construída em secção longitudinal ao Arroio esperança, cuja vazão média é de $1,7 \mathrm{~m}^{3} / \mathrm{s}$. Foi realizada uma coleta no ponto de mínima vazão (Qmín) entre 7 e 8 horas e outra no ponto de máxima vazão, (Qmáx) entre 14 e 15 horas, sem precipitação nas últimas 24 horas. A coleta de amostras foi realizada por meio de garrafas plásticas esterilizadas em solução de álcool 70\%. 


\section{ciênciaenatura UFSM, 34(2)}

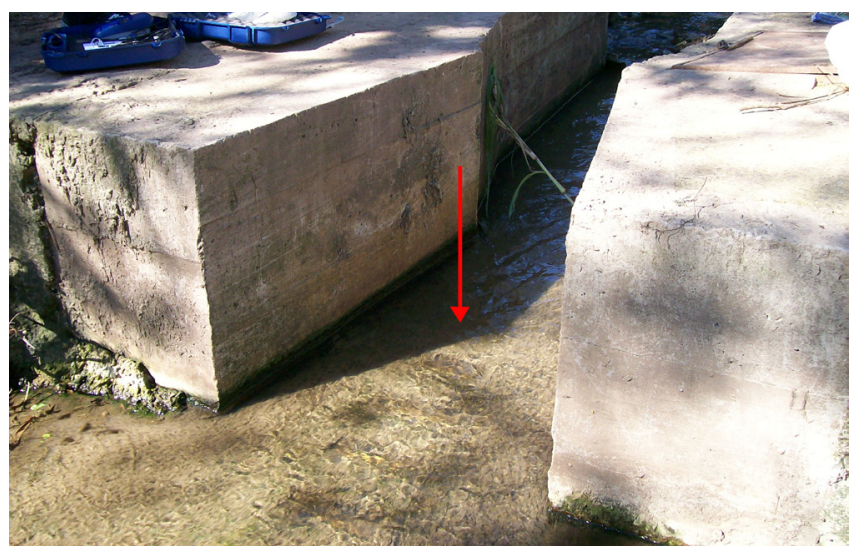

Figura 3 - Calha Parschall mostrando o ponto de amostragem no Arroio Esperança, Santa Maria, RS.

Para a avaliação e padronização da qualidade da água, utilizou-se o Índice de Qualidade da Água desenvolvido pelo National Sanitation Fundation (IQA-NSF). Esse índice reflete, principalmente, a contaminação dos corpos hídricos, ocasionada pelo lançamento de esgotos domésticos (CETESB 2006). O IQA-NSF é calculado por meio de uma equação aritmética simples (1), a qual utiliza parâmetros que representam suas características físico-químicas e biológicas, com seus respectivos pesos, conforme tabela 1 (IGAM, 2005), sendo o somatório dos pesos igual a 1,00.

sendo:

$$
I Q A=\coprod_{i=1}^{n} q i^{w i}
$$

IQA = Índice de Qualidade de Água, variando de o a 100;

qi = qualidade do parâmetro;

wi = peso atribuído ao parâmetro, em função de sua importância na qualidade, entre o e 1. 
Tabela 1- Parâmetros determinados e respectiva importância peso, conforme IGAM, 2005.

\begin{tabular}{lc}
\hline \multicolumn{1}{c}{ Parâmetro } & Peso - wi \\
\hline Oxigênio dissolvido - OD (\%ODSat) & 0,17 \\
Coliformes fecais (NMP/mL) & 0,15 \\
$\mathrm{pH}$ & 0,12 \\
Demanda bioquímica de oxigênio - $\mathrm{DBO}_{5}(\mathrm{mg} / \mathrm{L})$ & 0,10 \\
Nitratos $\left(\mathrm{mg} / \mathrm{L} \mathrm{NO}_{3}\right)$ & 0,10 \\
Fósforo $(\mathrm{mg} / \mathrm{L} \mathrm{P})$ & 0,10 \\
Variação na temperatura ${ }^{4}\left({ }^{\circ} \mathrm{C}\right)$ & 0,10 \\
Turbidez (UNT) & 0,08 \\
Resíduos totais fixos $(\mathrm{mg} / \mathrm{L})$ & 0,08 \\
\hline
\end{tabular}

${ }^{4}$ Variação da temperatura em relação a $20^{\circ} \mathrm{C}$.

A partir do cálculo efetuado, pode-se determinar a qualidade das águas brutas, que é definido pelo IQA, variando de o a 100, conforme a tabela 2 (IGAM, 2005).

Tabela 2 - Nível de Qualidade (IGAM, 2005).

\begin{tabular}{cc}
\hline IQA & Classificação \\
\hline $91-100$ & Excelente \\
$71-90$ & Bom \\
$51-70$ & Médio \\
$26-50$ & Ruim \\
$0-25$ & Muito Ruim \\
\hline
\end{tabular}

Também foram determinados os índices de qualidade (qs) para cada parâmetro, a fim de se destacar a importância de cada parâmetro na qualidade da água do arroio, conforme equações propostas por IGAM (2005).

No momento da coleta, foram determinados os parâmetros oxigênio dissolvido e temperatura da água pela leitura em um oxímetro da marca Digimed DM4. A determinação da turbidez foi realizada em laboratório através do turbidímetro SL-2K. A determinação dos resíduos totais fixos foi por meio de evaporação, utilizando bico de Bunsen e, em seguida, pesagem a seco. Para a determinação do $\mathrm{pH}$, utilizou-se um pH-metro da marca Analion pH-Metro. A $\mathrm{DBO}_{5}$ foi determinada pelo método de diluição e o resultado é a diferença do $\mathrm{OD}$ antes e depois do período de 
incubação. A metodologia para as análises desses parâmetros segue o recomendado por Macedo (2003). A determinação do número mais provável (NMP) de coliformes fecais foi realizada pelo método da diluição em tubos múltiplos e com o auxílio da tabela do NMP, de Alexander (1982).

O nitrato foi determinado por meio de destilação úmida de nitrogênio (BREMNER e KEENEY, 1965) e fósforo, determinado pela técnica colorimétrica, em espectrofotômetro (Biospectro - SP220 ${ }^{\circledR}$ ) UV-visível a $882 \mathrm{~nm}$ (MURPHY e RILEY, 1962).

Para ajustar à distribuição normal, os resultados foram submetidos à transformação $(\mathrm{X}+0,5)^{0,5}$ e posteriormente as médias foram comparadas pelo teste de Tukey ao nível de significância de 5\%, utilizando o programa estatístico SISVAR (FERREIRA, 2008).

\section{Resultado e Discussão}

Observa-se que somente dois valores de OD foram superiores ao estabelecido na legislação (CONAMA, 357/05), segundo a qual os valores de OD devem ser superiores a 4mg/L (Tabela 3). Tamanini et al. (1999) realizaram análises fisicoquímicas e microbiológicas nas águas do Arroio Esperança e também obtiveram baixos valores de oxigênio dissolvido, indicando "pontos mortos" no arroio e má qualidade da água, devido à elevada concentração de substâncias orgânicas e inorgânicas. Desse modo, a água do Arroio Esperança apresenta valores críticos à sobrevivência de formas aeróbicas de vida e indica também a presença de matéria orgânica, provavelmente de esgotos (VON SPERLING, 1996).

Tabela 3 - Temperatura $-\mathrm{T}\left({ }^{\circ} \mathrm{C}\right)$, $\mathrm{pH}$, oxigênio dissolvido (OD), demanda bioquímica de oxigênio (DBO), turbidez, coliformes fecais (CF), nitrato $\left(\mathrm{NO}_{3}\right)^{-}$, fósforo (P) e resíduos totais fixos (RTF), determinados na água do Arroio Esperança em Santa Maria-RS, nos meses de julho, agosto, setembro e outubro de 2007 , nos pontos de mínima (min) e máxima (máx) vazão. Média de três repetições.

\begin{tabular}{|c|c|c|c|c|c|c|c|c|c|c|}
\hline \multirow[t]{3}{*}{$\begin{array}{l}\text { Parâ- } \\
\text { metro }\end{array}$} & \multicolumn{2}{|c|}{ Julho } & \multicolumn{2}{|c|}{ Agosto } & \multicolumn{2}{|c|}{ Setembro } & \multicolumn{2}{|c|}{ Outubro } & \multicolumn{2}{|c|}{ Média } \\
\hline & \multicolumn{10}{|c|}{ - } \\
\hline & mín & máx & mín & máx & mín & máx & mín & máx & mín & máx \\
\hline $\mathrm{T}\left({ }^{\circ} \mathrm{C}\right)$ & 11,8 & 15,1 & 11,6 & 17,5 & 17,5 & 20,0 & 19,5 & 22,1 & $15,1 * \mathrm{~b}$ & $18,7 \mathrm{a}$ \\
\hline $\mathrm{pH}$ & 6,3 & 6,3 & 7,5 & 7,4 & 6,5 & 6,8 & 6,8 & 5,8 & $6,8 \mathrm{a}$ & $6,6 \mathrm{a}$ \\
\hline
\end{tabular}




\begin{tabular}{|c|c|c|c|c|c|c|c|c|c|c|}
\hline $\begin{array}{c}\text { OD } \\
\mathrm{mg} \mathrm{L}^{-1}\end{array}$ & 5,6 & 2,2 & 3,2 & 2,3 & 3,5 & 2,8 & 2,2 & 4,8 & 3,6a & $3,0 \mathrm{a}$ \\
\hline $\begin{array}{c}\mathrm{DBO} \\
\mathrm{mg} \mathrm{L}^{-1}\end{array}$ & 93,0 & 50,0 & 97,0 & 51,0 & 109,0 & 83,0 & 66,0 & 74,0 & $91,3 a$ & $64,5 b$ \\
\hline $\begin{array}{l}\text { Turbi- } \\
\text { dez } \\
\text { (NTU) }\end{array}$ & 7,5 & 16,3 & 18,0 & 22,0 & 5,8 & 10,4 & 11,0 & 22,5 & $10,6 b$ & $17,8 \mathrm{a}$ \\
\hline $\begin{array}{c}\mathrm{CF} \\
\mathrm{NMP} \\
\mathrm{mL}^{-1}\end{array}$ & 450 & 520 & 1200 & 1530 & 1300 & 1200 & 900 & 450 & $963 a$ & $925 a$ \\
\hline $\begin{array}{c}\mathrm{P} \\
\mathrm{mg} \mathrm{L}^{-1}\end{array}$ & 0,11 & 0,20 & 0,15 & 0,19 & 0,13 & 0,12 & 0,19 & 0,17 & $0,15 a$ & o,17a \\
\hline $\begin{array}{c}\mathrm{NO}_{3}^{-} \\
\mathrm{mg} \mathrm{L}^{-1}\end{array}$ & 1,02 & 0,26 & 0,85 & 0,93 & 0,75 & 0,8 & 0,85 & 0,71 & o,87a & $0,68 \mathrm{a}$ \\
\hline $\begin{array}{c}\text { RTF } \\
\mathrm{mg} \mathrm{L}^{-1}\end{array}$ & 280 & 440 & 140 & 360 & 120 & 200 & 130 & 200 & $168 b$ & $300 a$ \\
\hline
\end{tabular}

* Média com mesma letra, na linha, não difere pelo teste de Tukey a 5\% de probabilidade.

Os valores de fósforo e nitrato apresentados na tabela 3, não ultrapassam o estipulado para águas doces de classe 3 (CONAMA, 357/05). O fósforo é um nutriente essencial para os microorganismos responsáveis pela estabilização da matéria orgânica. É também elemento indispensável ao crescimento de algas e, quando em grandes quantidades, pode levar ao processo de eutrofização de um recurso hídrico (RICHTER e NETTO, 1995). Juntamente com o nitrato, que, quando presente em grandes quantidades em lagos ou reservatórios pode favorecer o desenvolvimento exagerado de microorganismos provenientes de contaminação por excretas (AZEVEDO NETTO, 1991), representa um indicador de poluição inorgânica. No entanto, no Arroio Esperança, fósforo e nitrato não apresentaram altas concentração e, portanto, não contribuem para a má qualidade da água.

Os valores de DBO variam entre $66 \mathrm{mg} / \mathrm{L}$ e $109 \mathrm{mg} / \mathrm{L}$ no momento de mínima vazão e entre $50 \mathrm{mg} / \mathrm{L}$ e $83 \mathrm{mg} / \mathrm{L}$ no momento de máxima vazão (Tabela 3). Percebe-se que todos os valores de DBO são superiores ao índice permitido pela resolução 357/05 do CONAMA, que é de 10 $\mathrm{mg} / \mathrm{L}$ para um rio de classe III. Esses valores indicam presença de matéria orgânica, que pode induzir a uma redução do oxigênio na água, provocando o desaparecimento de peixes e outras formas de vida aquática 
(CETESB, 2003). Portanto, os altos valores de DBO contribuem significativamente para a deterioração da qualidade da água do arroio.

A temperatura e o $\mathrm{pH}$ não apresentam variação significativa em relação à legislação, portanto não interferiram na qualidade da água (Tabela 3). Os resultados referentes ao $\mathrm{pH}$ indicam que ele se aproximou da neutralidade em todas as amostras e está dentro do limite estipulado pela legislação (CONAMA, 357/05), que fixa valores de pH entre 6 e 9 . A temperatura variou entre $11,6^{\circ} \mathrm{C}$ e $22,1^{\circ} \mathrm{C}$, refletindo a época do ano em que foram coletadas as amostras.

A turbidez e os resíduos totais fixos podem interferir na penetrabilidade de luz, impossibilitando as atividades fisiológicas dos microrganismos (CETESB, 2003). Dos resíduos totais fixos, fazem parte os constituintes da alcalinidade, dureza e também o nitrogênio e o fósforo (VON SPERLING, 2003). Os resultados encontrados nas determinações de resíduos totais fixos e turbidez (Tabela 3 ) foram inferiores ao fixado pela legislação (CONAMA, 357/05), que é de $500 \mathrm{mg} / \mathrm{L}$ para sólidos totais fixos e até 100 NTU para turbidez. Portanto, pode-se inferir que tanto a turbidez da água como os resíduos totais fixos não foram responsáveis pela alteração na qualidade da água do arroio Esperança.

Os valores de coliformes fecais (Tabela 3) estão inferiores ao estipulado pela resolução 357/05 do CONAMA. Cargnin et al. (2002), realizando monitoramento microbiológico das águas do arroio Esperança, no período de setembro de 1998 a maio de 2001 , obtiveram resultados referentes aos testes colimétricos maiores que os níveis toleráveis estabelecidos pela resolução 357/05 do CONAMA, evidenciando a contaminação das águas por fezes humanas e/ou animais. Desse modo, os valores de coliformes fecais obtidos neste trabalho, não contribuem significativamente para a diminuição da qualidade do arroio. Entretanto, conforme Richter e Netto (1995a), a presença de coliformes indica a possibilidade de haver contaminação da água por esgotos domésticos e o consumo da água contaminada por esses microrganismos associado a diversas doenças entéricas.

Os valores do Índice de Qualidade da Água (IQA) do Arroio Esperança variaram entre 32,2 para o mês de julho, no momento de Qmáx, e 41,o também para julho, no momento de Qmín (Figura 4). Esses valores permitiram a classificação da água analisada como ruim (IGAM, 
2005). O resultado reflete o observado "in loco", pois a área representa esgoto a céu aberto, áreas de erosão, degradação vegetal e transporte de lixo, devido ao acúmulo nas margens (Figura 5). Molina et al. (2006) obteve resultados semelhantes, nos quais foi observada grande presença de lixo doméstico nas margens do córrego Água na Bomba no município Regente Feijó-SP. Segundo o mesmo autor, a principal causa da alteração da qualidade da água foi o esgoto doméstico. Portanto, a dinâmica de uso e ocupação do solo de forma desordenada na área da Microbacia Urbana do Arroio Esperança contribui substancialmente para a degradação da qualidade da água, e o fator determinante se deve às cargas poluidoras de origem doméstica (esgotos sanitários e resíduos sólidos)

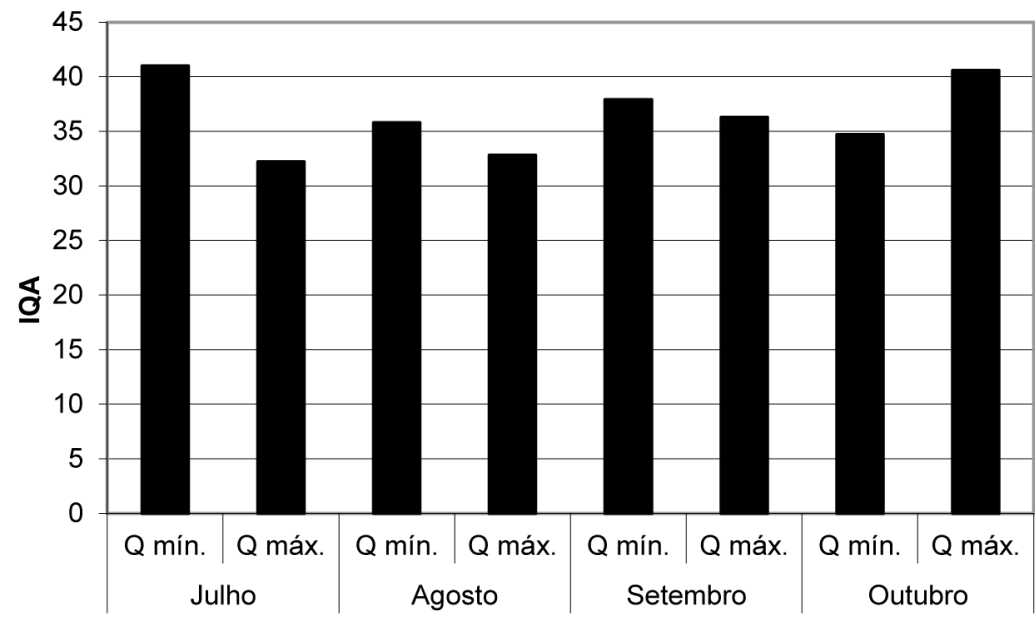

Coleta de Amostras.

Figura 4 - Valores de IQA obtidos nos meses de julho, agosto, setembro e outubro de 2007, nos pontos de mínima (Qmín) e máxima (Qmáx) vazão, do Arroio Esperança. 


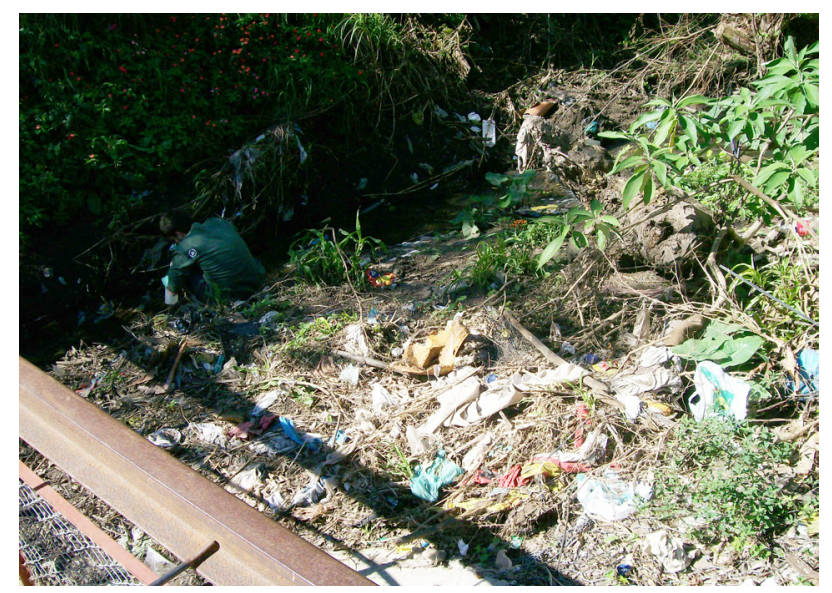

Figura 5 - Acúmulo de lixo nas margens do Arroio Esperança em Santa Maria-RS.

A determinação individual do IQA indica que a DBO foi o principal parâmetro responsável pela degradação da qualidade da água do Arroio Esperança, seguido pelo OD (Tabela 4). Esses parâmetros são inversamente proporcionais, ou seja, quanto menos oxigênio estiver presente no meio para estabilização da matéria orgânica, consequentemente, maiores serão as taxas de DBO (SPERLING, 1996). Nos meses de março, abril, maio e junho de 2007, outro estudo apontou os mesmos parâmetros como redutores da qualidade da água do Arroio Esperança (SANTOS, 2007). Os coliformes fecais também contribuíram para o baixo valor do índice de qualidade da água. Isso pode ser observado no mês de agosto, quando, na Qmáx do Arroio Esperança, foi verificado o menor valor de IQA. Esses resultados permitem inferir que o lançamento de matéria orgânica está influenciando as concentrações desses parâmetros, reduzindo assim a qualidade da água. Os altos índices de coliformes fecais encontrados demonstram problemas de saneamento no arroio.

Tabela 4 - Índice qs para Temperatura - T (ffC), pH, oxigênio dissolvido (OD), demanda bioquímica de oxigênio (DBO), turbidez, coliformes fecais $(\mathrm{CF})$, nitrato $\left(\mathrm{NO}_{3}\right)$ ), fósforo $(\mathrm{P})$ e resíduos totais fixos (RTF), determinados na água do Arroio Esperança em Santa Maria-RS, nos meses de julho, agosto, setembro e outubro de 2007, nos pontos de mínima (min) e máxima (máx) vazão, analisados conforme curva específica de qualidade (IGAM, 2005). Média de três repetições. 


\begin{tabular}{|c|c|c|c|c|c|c|c|c|}
\hline \multirow[t]{3}{*}{ Parâmetros } & \multicolumn{2}{|c|}{ Julho } & \multicolumn{2}{|c|}{ Agosto } & \multicolumn{2}{|c|}{ Setembro } & \multicolumn{2}{|c|}{ Outubro } \\
\hline & \multicolumn{8}{|c|}{ 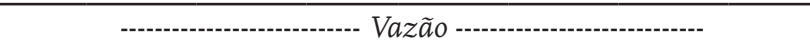 } \\
\hline & mín & máx & mín & máx & mín & máx & mín & máx \\
\hline $\mathrm{T}\left({ }^{\circ} \mathrm{C}\right)$ & 93 & 110,7 & 116,5 & 93,9 & 115,3 & 109,6 & 115,3 & 116,5 \\
\hline $\mathrm{pH}$ & 69,4 & 70,9 & 95,1 & 95,1 & 77 & 86 & 85,7 & 51,4 \\
\hline $\begin{array}{l}\text { OD } \\
\mathrm{mg} \mathrm{L}^{-1}\end{array}$ & 47 & 14 & 20,6 & 15,9 & 29,3 & 23 & 16,1 & 51,9 \\
\hline $\begin{array}{l}\mathrm{DBO} * \\
\mathrm{mg} \mathrm{L}^{-1}\end{array}$ & 2 & 2 & 2 & 2 & 2 & 2 & 2 & 2 \\
\hline $\begin{array}{l}\text { Turbidez } \\
\text { (NTU) }\end{array}$ & 82,5 & 69,2 & 66,9 & 61,9 & 85,4 & 77,8 & 76,9 & 61,3 \\
\hline $\begin{array}{l}\mathrm{CF} \\
\mathrm{NMP} \mathrm{mL}^{-1}\end{array}$ & 26,3 & 25,2 & 19,4 & 17,9 & 18,9 & 19,4 & 21,3 & 26,3 \\
\hline $\begin{array}{l}\mathrm{P} \\
\mathrm{mg} \mathrm{L}^{-1}\end{array}$ & 87,1 & 78,5 & 83 & 79,3 & 85 & 86 & 79,3 & 81,1 \\
\hline $\begin{array}{l}\mathrm{NO}_{3}^{-} \\
\mathrm{mg} \mathrm{L}^{-1}\end{array}$ & 89,7 & 95 & 90,8 & 90,3 & 91,5 & 91,2 & 90,8 & 91,8 \\
\hline $\begin{array}{l}\text { RTF } \\
\text { mg L-1 }^{-1}\end{array}$ & 64,1 & 40,6 & 82,1 & 82,5 & 83,5 & 75,7 & 82,9 & 75,7 \\
\hline
\end{tabular}

* Quando a DBO for maior que $30 \mathrm{mg} \mathrm{L}{ }^{-1}$, adota-se $q s=2,0$ para todos os valores de DBO (qs: índice de qualidade para cada parâmetro) (IGAM, 2005).

\section{Conclusão}

A qualidade da água na Microbacia urbana do Arroio Esperança, localizado em Santa Maria - RS, nos meses de julho, agosto, setembro e outubro, é considerada ruim pelo Índice de Qualidade da Água (IQA).

A DBO, OD e os coliformes fecais são os parâmetros que mais contribuem para a degradação da qualidade da água do Arroio Esperança.

\section{Referências}

ALEXANDER, M. Most probable number method for microbial populations. A.L. Page (ED.), Methods of Soil Analysis. Part 2. Chemical and Microbiological properties. American Society of Agronomy. Madson, Wi, USA. 1982. P. $815-820$.

AZEVEDO, N.; NETTO, M. H. C. B. Manual de Saneamento de Cidades e Edificações. Ed. São Paulo Pini, 1991. 
BILICH, M. R.; LACERDA, M. P. C. Avaliação da qualidade da água do Distrito Federal (DF), por meio de geoprocessamento. In: XII Simpósio Brasileiro de Sensoriamento Remoto. Anais. Goiânia-GO: 16 a 21 de abril de 2005. p. 2059-2065.

BREMNER, J.M.; KEENEY, D.R. Steam destilation methods for determination of ammonia, nitrate and nitrite. Anal Chemistry Acta, Amsterdam, v. 32, p. 485-495, 1965 .

BROWN, R. M. et al. "A water quality index - do we dare?” Water and Sewage Works. October. 1970. p. 339-343

COMITESINOS, Comitê de preservação, gerenciamento e pesquisa da bacia do Rio dos Sinos. Programa Integrado de Monitoramento da Qualidade da Água do Rio dos Sinos e seus Afluentes. Aplicação de um Índice de Qualidade da Água no Rio dos Sinos. Relatório Técnico. Porto Alegre. 33p. 1990.

BRANCO, S. M.; PORTO, M. F. A.; DE LUCA, S. J. Caracterização da qualidade da água. In: PORTO, R. L.L. (Org.) Hidrologia Ambiental. São Paulo: Editora da Universidade de São Paulo: Associação Brasileira de Recursos Hídricos, 1991. p. 27-66 (Coleção ABRH de Recursos Hídricos,; v. 3)

CARGNiN, R. H. O. et al. Monitoramento Microbiológico das Águas do Arroio Cadena, no Período de Setembro de 1998 a maio de 2001. In: XIV Salão de Iniciação Científica da Universidade Federal do Rio Grande do Sul. Porto Alegre. 2002.

CERETTA, M. C. Avaliação dos Aspectos da Qualidade da água na Microbacia Hidrográfica do Arroio Cadena - Município de Santa Maria-RS. Dissertação apresentada ao Curso de Mestrado do Programa de Pós-Graduação em Engenharia Civil, Área de Concentração em Recursos Hídricos e Saneamento Ambiental, da Universidade Federal de Santa Maria (UFSM, RS). 2004.

CETESB, Secretaria dos Serviços e Obras Públicas. Água qualidade, padrões de potencialidade e poluição. São Paulo,SP: CETESB, 2003.

Secretaria dos Serviços e Obras Públicas. 2006. Relatório de Qualidade das Águas Interiores do Estado de São Paulo - 2006. São 
Paulo: CETESB. Disponível em:<www.cetesb.sp.gov.br> Acesso em: 20 abr. 2007.

CONAMA. Conselho Nacional do Meio Ambiente. Resolução Normativa $\mathrm{N}^{\circ} 357$ de 17 de Março. 2005 .

CORRÊA, M. S. Como cuidar da nossa água. São Paulo, SP: Bei, 2004.

FERREIRA, Daniel Furtado. SISVAR: um programa para análises e ensino de estatística. Revista Symposium, Editora Lavras, v.6, p.36-41, 2008.

IGAM - INSTITUTO MINEIRO DE GESTÃO DAS ÁGUAS. 2005 . Sistema de Cálculo de Índice de Qualidade de Água (SCQA) - Estabelecimento das Equações do índice de Qualidade das Águas (IQA).Belo Horizonte: IGAM, 2005.Disponível em: <www.igam.mg.gov.br> Acesso em: 22 mar. 2007 .

MACÊDO, J. A. B. Métodos laboratoriais de análises: físico-químicas e microbiológicas. $2 \mathrm{ffl}$ ed. Belo Horizonte, MG: CRQ, 2003.

MELLO, L. F. da S. et al. Proposições para Restauração e Reurbanização de Áreas Limítrofes do Arroio Cadena. Santa Maria: UFSM, 1996. 16op.

MERTEN, G. H.; MINELLA, J. P. Qualidade da água em bacias hidrográficas rurais: um desafio atual para a sobrevivência futura. Agroecologia e Desenvolvimento Rural Sustentável. Porto Alegre, v. 3, n.4, out/dez. 2002.

MOLINA, P. M. Índice De Qualidade De Água Na Microbacia Degradada Do Córrego Água Da Bomba - Município De Regente Feijó - Sp, In XVI CONGRESSO NACIONAL DE IRRIGAÇÃO E DRENAGEM, 2006 Goiânia. Anais. Goiânia-GO: 25 a 30 de julho de 2006.

MURPHY, J.; RILEY, J.P. A modified single solution method for the determination of phosphate in natural waters. Anal. Chem. Acta., Amsterdam, v. 27, p. 31-36, 1962.

NUVOLARI, A. Esgoto Sanitário: coleta transporte tratamento e reuso agrícola. São Paulo: Edgard Blücher, 2003. 
SANTOS, J. F. Qualidade da Água na Microbacia Urbana do Arroio Cadena. Trabalho Final de Graduação pelo Centro Universitário Franciscano-UNIFRA. Santa Maria-RS, 2007.

TAMANINI, J. Z. et al. Análise Físico-Química e Microbiológica da Água do Arroio Cadena. In: 51a Reunião Anual da SBPC. Pontifícia Católica do Rio Grande do Sul. Porto Alegre. 1999.

TUDINSI, J. G. Água no século XXI: enfrentando a escassez. São Carlos, SP: Rima, 2003.

TUNDISI, J. G. A Água. São Paulo, SP: Publifolha, 2005.

RICHTER, C. A.; NETTO, J. M. de A. Tratamento de Água. Ed. São Paulo Edgar Blucher, 1995.

UCKER, F.E.; FOLETTO, C.; KEMERICH, P.D.C. Índice de Qualidade da Água em Bacia-Escola Urbana na Cidade de Santa Maria - RS. Engenharia Ambiental, Espírito Santo do Pinhal, v. 6, n. 3, set/dez 2009, p. $660-670$.

VON SPERLING, M. Introdução à qualidade das águas e ao tratamento de esgotos. 2 ed. Belo Horizonte, MG: DESA, 1996.

VON SPERLING, M. Introdução à qualidade das águas e ao tratamento de esgotos. 2. ed. Belo Horizonte: DESA - UFMG, 2003.

Submetido em: 04/10/2010

Aceito em: 02/01/2012 